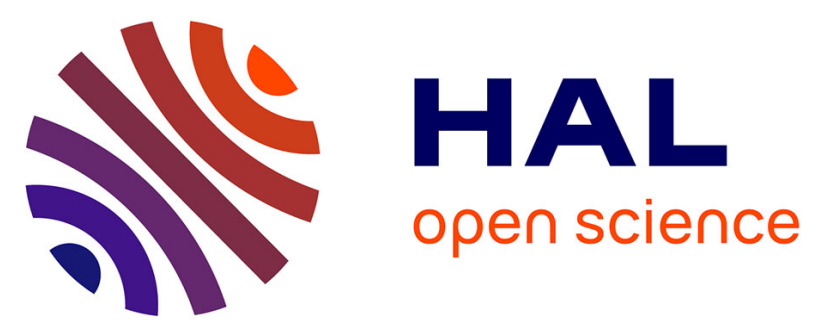

\title{
Gene-nutrient interactions on the phosphoenolpyruvate carboxykinase influence insulin sensitivity in metabolic syndrome subjects
}

Pablo Pérez-Martinez, Antonio Garcia-Rios, Javier Delgado-Lista, Ingrid M.F. Gjelstad, James Gibney, Beata Kie C-Wilk, Antonio Camargo, Olfa Helal, Brita Karlstrom, Ellen E. Blaak, et al.

\section{To cite this version:}

Pablo Pérez-Martinez, Antonio Garcia-Rios, Javier Delgado-Lista, Ingrid M.F. Gjelstad, James Gibney, et al.. Gene-nutrient interactions on the phosphoenolpyruvate carboxykinase influence insulin sensitivity in metabolic syndrome subjects. Clinical Nutrition, 2013, 32 (4), pp.630-635. 10.1016/j.clnu.2012.10.003 . hal-02645013

\section{HAL Id: hal-02645013 https://hal.inrae.fr/hal-02645013}

Submitted on 29 May 2020

HAL is a multi-disciplinary open access archive for the deposit and dissemination of scientific research documents, whether they are published or not. The documents may come from teaching and research institutions in France or abroad, or from public or private research centers.
L'archive ouverte pluridisciplinaire $\mathbf{H A L}$, est destinée au dépôt et à la diffusion de documents scientifiques de niveau recherche, publiés ou non, émanant des établissements d'enseignement et de recherche français ou étrangers, des laboratoires publics ou privés. 
Version définitive du manuscrit publiée dans / Final version of the manuscript published in :

Applied mathematics letters (2013), Vol. 26, N.8, p. 831-835, DOI: 10.1016/j.aml.2013.03.005

Journal homepage: http://arxiv.org/abs/1302.0949

\title{
Gene-nutrient interactions on the phosphoenolpyruvate carboxykinase influence insulin sensitivity in metabolic syndrome subjects
}

\author{
Pablo Perez-Martinez ${ }^{\text {a,b,m }}$, Antonio Garcia-Rios ${ }^{\mathrm{a}, \mathrm{b}, \mathrm{m}}$, Javier Delgado-Lista ${ }^{\mathrm{a}, \mathrm{b}}$, \\ Ingrid M.F. Gjelstad ${ }^{\mathrm{c}, \mathrm{d}}$, James Gibney ${ }^{\mathrm{e}}$, Beata Kieć-Wilk ${ }^{\mathrm{f}, \mathrm{g}}$, Antonio Camargo ${ }^{\mathrm{a}, \mathrm{b}}$, \\ Olfa Helal $^{\mathrm{h}}$, Brita Karlström ${ }^{\mathrm{i}}$, Ellen E. Blaak ${ }^{\mathrm{j}}$, Wendy Hall ${ }^{\mathrm{k}}$, Ulf Risérus ${ }^{\mathrm{i}}$, \\ Aldona Dembińska-Kieć ${ }^{\text {f,g }}$, Catherine Defoort ${ }^{\mathrm{h}}$, Wim H.M. Saris ${ }^{\mathrm{j}}$, \\ Julie A. Lovegrove ${ }^{\mathrm{k}}$, Christian A. Drevon ${ }^{\mathrm{d}}$, Helen M. Roche ${ }^{\mathrm{l}, \mathrm{n}}$, Jose Lopez-Miranda ${ }^{\mathrm{a}, \mathrm{b}, *, \mathrm{n}}$ \\ ${ }^{a}$ Lipid and Atherosclerosis Research Unit, IMIBIC, Reina Sofia University Hospital, University of Cordoba, Avda. Menéndez Pidal, s/n. 14004 Córdoba, Spain \\ ${ }^{\mathrm{b}}$ CIBER Fisiopatologia Obesidad y Nutricion (CIBEROBN), Instituto de Salud Carlos III, Spain \\ ${ }^{\mathrm{c}}$ Department of Endocrinology, Oslo University Hospital, Oslo, Norway \\ ${ }^{\mathrm{d}}$ Department of Nutrition, Institute of Basic Medical Sciences, Faculty of Medicine, University of Oslo, Norway \\ ${ }^{\mathrm{e}}$ Department of Endocrinology, Adelaide and Meath Hospital, Incorporating the National Children's Hospital, Dublin, Ireland \\ ${ }^{\mathrm{f}}$ Department of Clinical Biochemistry, Jagiellonian University Medical College, Krakow, Poland \\ ${ }^{\mathrm{g}}$ Department of Metabolic Diseases, Jagiellonian University Medical College, Krakow, Poland \\ ${ }^{\mathrm{h}}$ INSERM 476, Lipid Nutrients and Prevention of Metabolic Diseases, INRA 1260, Université de la Méditerranée, Marseille, France \\ ${ }^{\mathrm{i}}$ Clinical Nutrition and Metabolism, Department of Public Health and Caring Sciences, Uppsala University, Uppsala, Sweden \\ ${ }^{\mathrm{j}}$ Department of Human Biology, NUTRIM, School for Nutrition, Toxicology and Metabolism, Maastricht, The Netherlands \\ ${ }^{\mathrm{k}}$ Department of Food and Nutritional Sciences and the Institute for Cardiovascular and Metabolic Research, University of Reading, Reading, \\ Berkshire RG6 6AP, UK \\ ${ }^{1}$ Nutrigenomics Research Group, UCD School of Public Health and Population Science, UCD Conway Institute, University College Dublin, Ireland
}

Keywords:

HOMA-IR

Metabolic syndrome

$n-3$ polyunsaturated fatty acids

PCK1 gene

Adipose tissue

Nutrigenetics

\section{S U M M A R Y}

Background \& aims: Genetic background may interact with habitual dietary fat composition, and affect development of the metabolic syndrome (MetS). The phosphoenolpyruvate carboxykinase gene (PCK1) plays a significant role regulating glucose metabolism, and fatty acids are key metabolic regulators, which interact with transcription factors and influence glucose metabolism. We explored genetic variability at the PCK1 gene locus in relation to degree of insulin resistance and plasma fatty acid levels in MetS subjects. Moreover, we analyzed the PCK1 gene expression in the adipose tissue of a subgroup of MetS subjects according to the PCK1 genetic variants.

Methods: Insulin sensitivity, insulin secretion, glucose effectiveness, plasma concentrations of C-peptide, fatty acid composition and three PCK1 tag-single nucleotide polymorphisms (SNPs) were determined in 443 MetS participants in the LIPGENE cohort.

Results: The rs2179706 SNP interacted with plasma concentration of $n-3$ polyunsaturated fatty acids ( $n-3$ PUFA), which were significantly associated with plasma concentrations of fasting insulin, peptide C, and HOMA-IR. Among subjects with $n-3$ PUFA levels above the population median, carriers of the $\mathrm{C} / \mathrm{C}$ genotype exhibited lower plasma concentrations of fasting insulin $(P=0.036)$ and HOMA-IR $(P=0.019)$ as compared with $C / C$ carriers with $n-3$ PUFA below the median. Moreover, homozygous $\mathrm{C} / \mathrm{C}$ subjects with $n-3$ PUFA levels above the median showed lower plasma concentrations of peptide

Non-standard abbreviations: AIRg, acute insulin response to glucose; PEPCK-C, cytosolic phosphoenolpyruvate carboxykinase; DI, disposition index; HWE, Hardy-

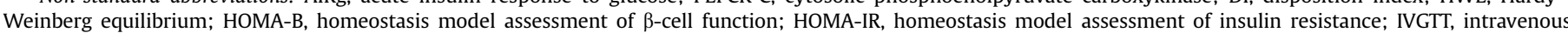

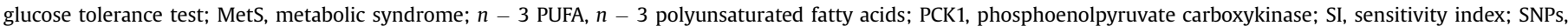
single nucleotide polymorphisms; T2D, type 2 diabetes.

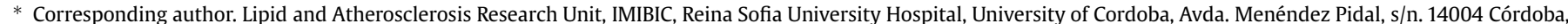
Spain. Tel.: +34 957010947; fax: +34 957218250.

E-mail address: jlopezmir@uco.es (J. Lopez-Miranda).

$m$ The first two authors PP-M and AG-R contributed equally to this study.

$\mathrm{n}$ The last two authors JL-M and HM-R contributed equally to this study. 


\begin{abstract}
C as compared to individuals with the T-allele $(P=0.006)$. Subjects carrying the T-allele showed a lower gene $P C K 1$ expression as compared with carriers of the $C / C$ genotype $(P=0.015)$.

Conclusions: The PCK1 rs2179706 polymorphism interacts with plasma concentration of $n-3$ PUFA levels modulating insulin resistance in MetS subjects.
\end{abstract}

\section{Introduction}

The pathogenesis of the metabolic syndrome (MetS) is complex and not completely understood but the interaction of overweight, physical inactivity, and genetic factors contribute to its development. The National Cholesterol Education Program-Adult Treatment Panel III has identified the MetS as an indication for intensive lifestyle intervention. ${ }^{1}$ Effective interventions include modifications in dietary habits and physical activity, and judicious use of pharmacologic agents for minimizing or delaying the comorbidities associated with the MetS. Epidemiological studies indicate that Westernstyle dietary patterns promote the MetS, while diets rich in fruits, vegetables, grains, fish and low-fat dairy products have a protective role. In this regards, dietary strategies to increase the intake of dietary antioxidants, and $n-3$ fatty acids will be helpful for improving health and reducing MetS. A recent intervention study ${ }^{2}$ demonstrated that consumption of a low-fat high-carbohydrate supplemented with $n-3$ PUFA acids reduced the risk of MetS and the prevalence of enlarged waist circumference, hypertension and hypertriacylglycerolemia were reduced. Thus, lifestyle modification has generally been accepted as a cornerstone of treatment for MetS, with the expectation that an appropriate intake of energy and nutrients will improve its control and reduce the risk of complications. ${ }^{3}$ However, some evidence suggests that some individuals are genetically predisposed to insulin resistance, and due to the complex nature of gene-environment interactions, dietary adjustment in subject with the MetS may require a personalized approach., ${ }^{4,5}$

Multiple candidate genes may affect primary insulin action, and particularly the interaction with diet is an important modulator of glucose metabolism and insulin resistance., ${ }^{6,7}$ The phosphoenolpyruvate carboxykinase gene (PCK1) is located on chromosome $20 \mathrm{q}$ and encodes the cytosolic phosphoenolpyruvate carboxykinase (PEPCK-C), ${ }^{8}$ which is the key enzyme involved in the regulation of gluconeogenesis, glyceroneogenesis and cataplerosis. Expression of PCK1 is under hormonal control, regulated at the transcriptional level by activators, such as glucagon, and inhibitors, such as insulin. It has been suggested that type 2 diabetes mellitus (T2D) could be caused by either excessive PEPCK-C production in the liver or reduced levels of PEPCK-C in adipose tissue. ${ }^{9}$ According to this hypothesis several single nucleotide polymorphisms (SNP) at the PCK1 locus have been associated with increased risk of T2D. ${ }^{10}$ Furthermore, Millward et al. have demonstrated that the promoter region of the PCK1 is essential for the regulation of triglyceride/fatty acid flux between adipose and liver tissues and it is important for the maintenance of glucose and lipid homeostasis and for prevention of insulin resistance. ${ }^{11}$ Thus, these data support the central position of PCK1 in pathways regulating fatty acids as well as glucose metabolism in humans. However, there are no studies exploring the interaction of polymorphisms in the PCK1 gene with the dietary fatty acid composition as a determinant of insulin resistance.

We investigated whether PCK1 genetic variants may influence glucose metabolism, including insulin secretion or insulin sensitivity measured after an intravenous glucose tolerance test (IVGTT), in response to different dietary supply of fatty acids among MetS subjects. Moreover, we analyzed the PCK1 gene expression in the adipose tissue of a subgroup of MetS subjects according to the PCK1 genetic variants.

\section{Methods}

Detailed design of the present study has been described previously $^{6,7}$ and summarized below.

\subsection{Subjects}

This study was performed in accordance with the Helsinki Declaration of 1975 as revised in 1983, and was approved by the local ethics committees at each centre. All subjects provided written informed consent before any study related procedure. The participants, aged $35-70$ years and BMI $20-40 \mathrm{~kg} / \mathrm{m}^{2}$, were recruited for the LIPGENE dietary intervention study from eight European countries (Ireland, UK, Norway, France, The Netherlands, Spain, Poland and Sweden). Subject eligibility was determined using a modified version of the NCEP criteria for the MetS, ${ }^{1}$ where subjects were required to fulfil at least three of the following five criteria: waist circumference $>102 \mathrm{~cm}$ (men) or $>88 \mathrm{~cm}$ (women); fasting plasma concentration of glucose $5.5-7.0 \mathrm{mmol} / \mathrm{L}$; TAG $\geq 1.5 \mathrm{mmol} / \mathrm{L} ; \mathrm{HDL}$ cholesterol $<1.0 \mathrm{mmol} / \mathrm{L}$ (men) or $<1.3 \mathrm{mmol} / \mathrm{L}$ (women); and blood pressure $\geq 130 / 85 \mathrm{mmHg}$, or treatment of previously diagnosed hypertension. The pre-intervention data for these subjects were published from the LIPGENE dietary intervention cohort elsewhere. ${ }^{12}$ Anthropometric measurements were recorded according to a standardized protocol for the LIPGENE study and blood pressure was measured following the guidelines of European Society of Hypertension. The present analyses include the 443 subjects with available SNP data. Of these participants, $68 \%$ received anti-hypertensive medication. Details of the inclusion and exclusion criteria of the LIPGENE study were published previously. ${ }^{13}$

\subsection{Biochemical measurements}

Plasma, serum, and buffy coat were prepared from $12 \mathrm{~h}$ fasting blood samples in each subject. Serum insulin and C-peptide were measured by a solid-phase, two-site fluoroimmunometric assay on a 1235 automatic immunoassay system (AutoDELFIA kits, Wallac Oy, Turku, Finland). Plasma glucose concentrations were measured using the IL Test ${ }^{\mathrm{TM}}$ Glucose Hexokinase Clinical Chemistry kit (Instrumentation Laboratories, Warrington, UK). Homeostasis model assessment of insulin resistance (HOMA-IR) was derived from fasting glucose and insulin levels [(fasting plasma glucose $\times$ fasting serum insulin)/22.5]. ${ }^{14}$ As HOMA-IR takes into account both insulin and glucose levels, it may be a more complete index than plasma insulin. Homeostasis model assessment of $\beta$-cell function (HOMA-B) was calculated as $[(20 \times$ fasting serum insulin $) /($ fasting plasma glucose - 3.5)]. An IVGTT was performed. Insulin sensitivity (sensitivity index, SI) and glucose effectiveness were determined using the MINMOD Millenium Program (version 6.02, Richard N Bergman). ${ }^{15}$ The acute insulin response to glucose (AIRg = first phase insulin response) was defined as the incremental area under the curve from time $0-8 \mathrm{~min}$. Disposition index (DI) was calculated as the product of AIRg and insulin sensitivity. Cholesterol and triglycerides were quantified using the IL Test ${ }^{\mathrm{TM}}$ Cholesterol kit and IL Test ${ }^{\mathrm{TM}}$ Triglycerides kit (Instrumentation Laboratories, Warrington, UK).

Fatty acids were extracted from plasma and transmethylated with boron trifluoride in methanol. Fatty acid methyl esters were 
analyzed by gas chromatography on a Shimadzu GC-14A (Shimadzu, Kyoto, Japan) fitted with a Shimadzu C-r6A integrator and a 25 M BP 21 polar aluminium silica column. Detector and injector temperatures were $260^{\circ} \mathrm{C}$ and $250^{\circ} \mathrm{C}$, respectively. Fatty acids were identified by the comparison of the relative retention times of plasma fatty acid methyl esters with fatty acid methyl esters standards. Fatty acid mass was measured as a relative percentage of the total quantified fatty acids. ${ }^{16}$ Total plasma $n-3$ PUFA was calculated from the sum of C18:3 $(n-3), \mathrm{C} 18: 4(n-3), \mathrm{C} 20: 4$ $(n-3), C 20: 5(n-3), C 22: 5(n-3)$ and C22:6 $(n-3)$. Long-chain (LC) $n-3$ PUFA was calculated from C20:5 $(n-3)$ and C22:6 $(n-3)$; and $n-6$ PUFAs from the sum of $18: 2,18: 3 n-6,20: 3$, $20: 4 n-6$, and 22:4.

\subsection{SNP selection and genotyping}

PCK1 genotype data from HapMap v1.1 (www.hapmap.org) was uploaded into HITAGENE, a web-based combined database and genetic analysis software suite. Haplotype frequencies were estimated by implementation of the expectation maximization algorithm. Using a 5\% cut-off for individual haplotype frequency and $>70 \%$ for the sum of all haplotype frequencies, haplotype tagged (HT) SNPs were identified using SNP tagger (www.broad.mit.edu/ mpg/tagger/server.html). Thus, the rs2071023, rs2179706, and rs6070157 polymorphisms were genotyped at the PCK1 gene by Illumina Inc., (San Diego, CA, USA). DNA was extracted from buffy coat samples using the AutoPure LS automated system (Gentra Systems Inc., Minneapolis, MN, USA), and low yielding samples $(<10 \mathrm{ng}$ ) were subjected to whole genome amplification using the REPLI-g kit (Qiagen Ltd. West Sussex, UK). Adherence to HardyWeinberg equilibrium (HWE) at each SNP locus was determined using the $\chi^{2}$ test with 1 degree of freedom.

\subsection{Subcutaneous adipose tissue biopsies}

Subcutaneous adipose tissue samples were obtained from the superficial abdominal subcutaneous adipose tissue lateral to the navel of 30 MetS subjects, with instrument Bard ${ }^{\circledR}$ Magnum (ref. MG1522) (Bard Biopsy Systems, Tempe, AZ, USA), needles Bard ${ }^{\circledR}$ Magnum Core (ref. MN1410). Immediately after extraction, samples were stored in Eppendorf tubes with RNA later tissue Collection (Applied Biosystems, Carlsbad, CA, USA) until RNA extraction.

\subsection{RNA isolation from adipose tissue}

Adipose tissue was homogenized using Ultra-Turrax T25 (IKA Labortechnik, Staufen, Germany). After removal of lipids from the top of the tube, RNA was isolated with a commercial kit RiboPure kit (Ambion, Applied Biosystems, Carlsbad, CA, USA). RNA was collected from the aqueous phase by binding to a fiber glass filter. The quantification of RNA was performed using the spectrophotometer v3.5.2 Nanodrop ND-1000 spectrophotometer (Nanodrop Technology ${ }^{\circledR}$, Cambridge, UK).

\subsection{Gene expression by reverse transcription polymerase chain reaction}

The reverse transcription was performed using the commercial kit MessageBOOSTER cDNA Synthesis kit for qPCR (Epicentre, Madison, WI, USA), according to the manufacturer instructions. Briefly, it was amplified $500 \mathrm{pg}$ of total RNA and then converted to CDNA, which was stored at $-20^{\circ} \mathrm{C}$. PCR analyses were performed using the OpenArray ${ }^{\mathrm{TM}}$ NT Cycler system (Applied Biosystems, Carlsbad, CA, USA) in samples from 30 MetS patients by duplicated, according to the manufacturer instructions. Briefly, each reaction was performed on $1.2 \mu \mathrm{L}$ of $1: 2(\mathrm{v} / \mathrm{v})$ dilution of the first cDNA strand, $2.5 \mu \mathrm{L}$ ABI Gene Amp Master Mix (Applied Biosystems), $1 \mu \mathrm{L}$ Remix (Applied Biosystems), $0.30 \mu \mathrm{L}$ of water. Reaction mix was loaded on the array by using OpenArray ${ }^{\mathrm{TM}}$ NT Autoloader (Applied Biosystems), according to the manufacturer's instruction. The reaction was incubated at $95^{\circ} \mathrm{C}$ for $10 \mathrm{~min}$, followed by 40 cycles of 5 min at $95^{\circ} \mathrm{C}, 2$ min at $58^{\circ} \mathrm{C}, 1 \mathrm{~min}$ at $72{ }^{\circ} \mathrm{C}$ on the OpenArray ${ }^{\mathrm{TM}} \mathrm{NT}$ Cycler (Applied Biosystems). Primer pairs were selected from the database TaqMan Gene Expression assays (Applied Biosystems, Carlsbad, CA, USA) https://bioinfo.appliedbiosystems.com/genomedatabase/gene-expression.html, for the following genes: PCK1 (Hs00159918_m1) and RPLPO (Hs99999902_m1) as housekeeping gene. Expression values were obtained as relative expression of the PCK1 gene versus the constitutively expressed RPLP0 gene (relative expression $=2-(\mathrm{Ct}$, Target gene $-\mathrm{Ct}$, Reference gene $)$ ).

\subsection{Statistical analysis}

Biochemical variables were assessed for normal distribution, and skewed variables were normalised by log 10 or square root transformation as appropriate. Statistical analyses were carried out using SPSS version 18.0 for Windows (SPSS Inc., Chicago, IL). Data are presented as means \pm standard error (SE) for continuous variables and as frequencies or percentages for categorical variables. Comparisons of frequencies between qualitative variables were carried out using the Chi-squared test. Potential confounding factors were age, sex, BMI, and LIPGENE centre of origin. ANOVAbased models were used to test for associations between individual SNP and the variables studied, with the SNP as fixed factor, and age, BMI, sex and centre of origin as covariates. The effect of each SNP interacting with groups of plasma fatty acids (omega-3 and omega- 6 polyunsaturated, saturated, monounsaturated) on each biochemical variable was investigated using the median of plasma fatty acids to dichotomize the population, and using the resulting groups (above the median versus below the median) as a fixed factor in combination with the SNP genotypes in a univariate ANOVA analysis with the same covariates and Bonferroni corrections as exposed above. Thus, in this model we could assess the associated effects of SNP alone, fatty acids alone and the interaction between the SNP and the fatty acids on the selected variables. Bonferroni's test was used in the post-hoc analysis. The normal distribution of PCK1 gene expression was assessed using the Kolmogorov-Smirnov test. The gene expression data were analyzed by using one-way ANOVA to determine the genotype effect on the PCK1 gene expression, with the SNP as fixed factor and age, BMI, gender, and centre of origin as covariates.

\section{Results}

We analyzed the effect of the three rs2071023, rs2179706, and rs6070157 SNPs at the PCK1 gene locus on glucose metabolism in relation to plasma fatty acid status. Baseline demographic and biochemical characteristics for the rs2179706 SNP are presented in Table 1. Genotype distributions did not deviate from HardyWeinberg expectations. No significant baseline differences were observed in relation to age, blood pressure, fasting lipids, glucose, insulin, peptide $\mathrm{C}$ and HOMA-IR concentration by genotype (Table 1). Although we did not observe any gene-nutrient interactions for the rs2071023 and rs6070157 SNPs these data are presented as supplementary material (Tables $1 \mathrm{~S}$ and $2 \mathrm{~S}$ ).

\subsection{Insulin sensitivity}

IVGTT and HOMA indices were used to estimate insulin sensitivity index (SI) and HOMA-IR. The rs2179706 SNP interacted with 
Version définitive du manuscrit publiée dans / Final version of the manuscript published in :

Applied mathematics letters (2013), Vol. 26, N.8, p. 831-835, DOI: 10.1016/j.aml.2013.03.005

Journal homepage: http://arxiv.org/abs/1302.0949

Table 1

Characteristics of participants with the PCK1 rs2179706 polymorphism at baseline.

\begin{tabular}{lllll}
\hline & rs2179706 & & P-value \\
\cline { 2 - 4 } & $\mathrm{C} / \mathrm{C}$ & $\mathrm{C} / \mathrm{T}$ & $\mathrm{T} / \mathrm{T}$ & \\
\hline$n$ & 151 & 192 & 100 & \\
Age, years & $54.54(0.7)$ & $54.65(0.6)$ & $53.46(0.8)$ & 0.531 \\
BMI, kg/m & $32.17(0.3)$ & $32.89(0.3)$ & $32.33(0.3)$ & 0.258 \\
Diastolic BP (mmHg) & $86.25(0.7)$ & $85.42(0.7)$ & $87.61(1)$ & 0.205 \\
Systolic BP (mmHg) & $137.58(1.3)$ & $139.37(1)$ & $140.32(1.6)$ & 0.366 \\
Total cholesterol, & $5.33(0.07)$ & $5.31(0.07)$ & $5.44(0.09)$ & 0.519 \\
$\quad$ mmol/L & & & & \\
LDL-C, mmol/L & $3.30(0.08)$ & $3.20(0.07)$ & $3.38(0.10)$ & 0.359 \\
HDL-C, mmol/L & $1.09(0.02)$ & $1.11(0.02)$ & $1.15(0.02)$ & 0.157 \\
TG, mmol/L & $1.68(0.06)$ & $1.88(0.07)$ & $1.75(0.07)$ & 0.103 \\
ApoB, g/L & $1.01(0.01)$ & $1.02(0.01)$ & $1.03(0.02)$ & 0.921 \\
Glucose (mmol/L) & $5.93(0.06)$ & $5.93(0.04)$ & $5.96(0.08)$ & 0.953 \\
Insulin (mU/L) & $9.97(0.5)$ & $10.08(0.4)$ & $10.61(0.5)$ & 0.671 \\
Peptide C (pmol/L) & $2.53(0.07)$ & $2.61(0.06)$ & $2.78(0.08)$ & 0.109 \\
HOMA-IR & $2.67(0.1)$ & $2.67(0.1)$ & $2.84(0.1)$ & 0.674 \\
\hline All & & & \\
\hline
\end{tabular}

All values are means $\pm \mathrm{SE}$. BP, blood pressure; TG, triglycerides; HOMA-IR homeostasis model assessment of insulin resistance.

plasma $n-3$ PUFA levels, which were significantly associated with plasma concentrations of fasting insulin, peptide C, and HOMA-IR. Among subjects with $n-3$ PUFA levels above the population median, carriers of the $\mathrm{C} / \mathrm{C}$ genotype exhibited lower plasma concentrations of fasting insulin $(P=0.036)$ and HOMA-IR $(P=0.019)$, as compared with $C / C$ carriers with plasma $n-3$ PUFA below the median (Fig. 1A and B). Moreover, homozygotes for C/C with $n-3$ PUFA levels above the median, showed lower plasma concentrations of peptide $C$ as compared with individuals with the T-allele ( $P=0.006)$ (Fig. 1C). SI did not differ between participants with different genotypes. There were no significant interactions between other groups of plasma fatty acids (SFA, MUFA and $n-6$ PUFA) and PCK1 SNPs on glucose metabolism. We also explored the genetic component independent of the nutrient effect, and no differences were observed. In a next step a linear regression model including the original covariates was applied to create predicted values of HOMA-IR according to genotype at the rs2179706 SNP (Fig. 2). The genotype groups exhibited striking differences in the predicted changes in HOMA-IR in relation to plasma $n-3$ PUFA concentrations. From baseline data, the model predicts that in $\mathrm{C} / \mathrm{C}$ individuals, an increase in plasma $n-3$ PUFA would elicit a considerable decrease in HOMA-IR (Fig. 2). An opposite effect was observed in subjects carrying the T-allele.

\subsection{Insulin secretion}

We also explored the effect of the rs2179706 on insulin secretion according to plasma levels of different fatty acids. For that purpose acute insulin response to glucose (AIRg), disposition index (DI) and HOMA-B were measured. In contrast to the insulin sensitivity findings, we did not observe any gene-nutrient interactions for these parameters.

\subsection{Adipose tissue gene expression}

We analyzed the PCK1 gene expression in the adipose tissue of a subgroup of MetS subjects with the rs2179706 polymorphism. Subjects carrying the T-allele showed a lower PCK1 gene expression as compared with carriers of the $C / C$ genotype $(P=0.015)$ (Fig. 3$)$.

\section{Discussion}

We identified that the PCK1 rs2179706 SNP influenced insulin resistance by interacting with plasma $n-3$ PUFA levels in MetS

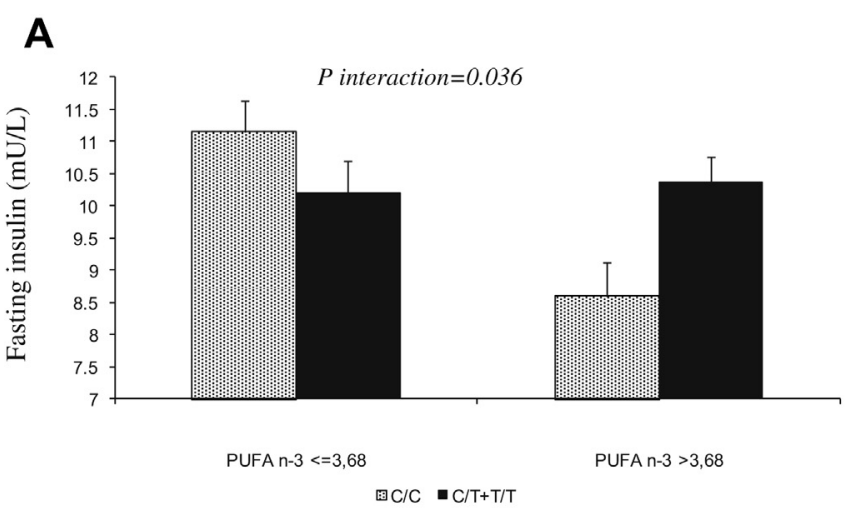

B

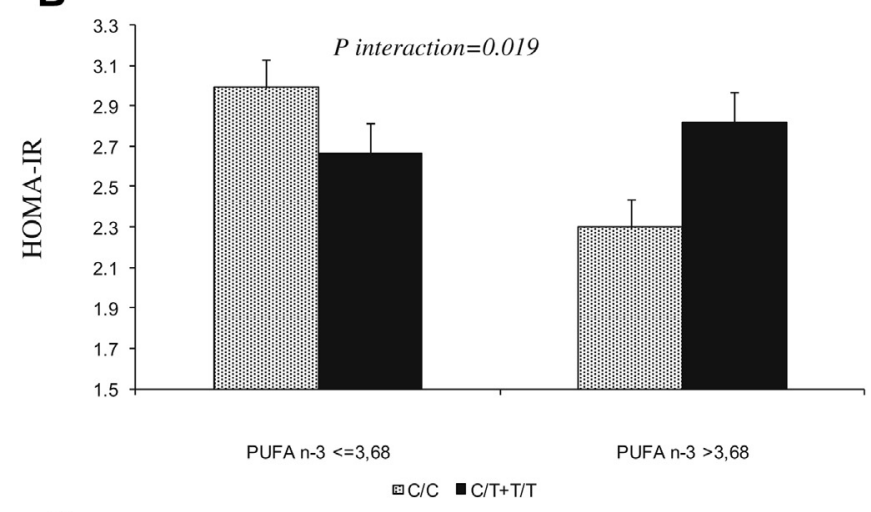

C

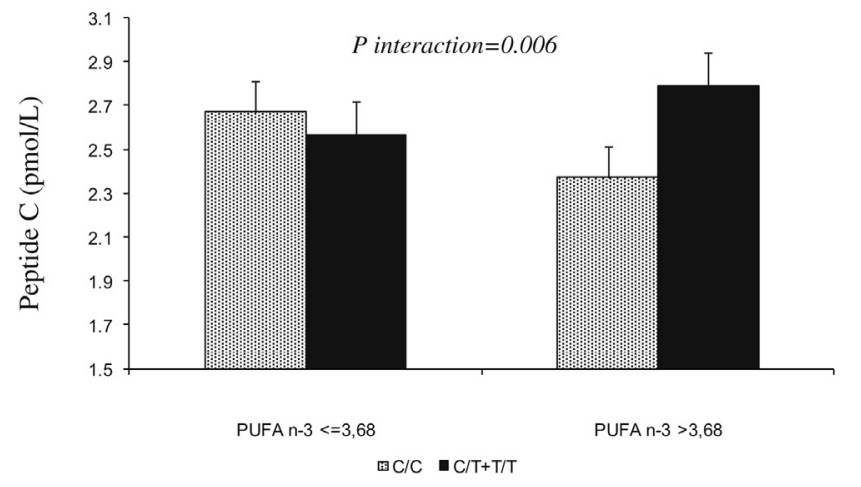

Fig. 1. Interaction between the rs 2179706 polymorphism and plasma concentrations of omega-3 polyunsaturated fatty acids ( $n-3$ PUFA), above or below the median within the same genotype group of fasting plasma concentration of of insulin (A), homeostasis model assessment of insulin resistance (HOMA-IR) $(\mathbf{B})$ and, peptide $\mathrm{C}(\mathbf{C})$. Values are means \pm SE. $P$ values were adjusted for age, sex, BMI, and LIPGENE centre of origin.

patients. Thus, among subjects with $n-3$ PUFA levels above the population median, carriers of the $\mathrm{C} / \mathrm{C}$ genotype exhibited lower plasma concentrations of fasting insulin and HOMA-IR as compared with C/C carriers with $n-3$ PUFA below the median. Moreover, homozygotes for $\mathrm{C} / \mathrm{C}$ with $n-3$ PUFA levels above the median showed lower plasma concentrations of peptide $C$ as compared with individuals with the T-allele. This new knowledge about the relationship between genetic and environmental components may facilitate the choice of more effective diet for MetS prevention based on the personalized nutrition.

Over the last few years further attention has been paid to the quality of dietary fat. The plasma fatty acid composition has been determined as a biomarker of habitual dietary fat intake, reflecting the combination of dietary fat consumption and endogenous de novo fatty acid biosynthesis and metabolism. Previous evidence supports the notion that $n-3$ PUFAs are effective in preventing 
Version définitive du manuscrit publiée dans / Final version of the manuscript published in :

Applied mathematics letters (2013), Vol. 26, N.8, p. 831-835, DOI: 10.1016/j.aml.2013.03.005

Journal homepage: http://arxiv.org/abs/1302,0949

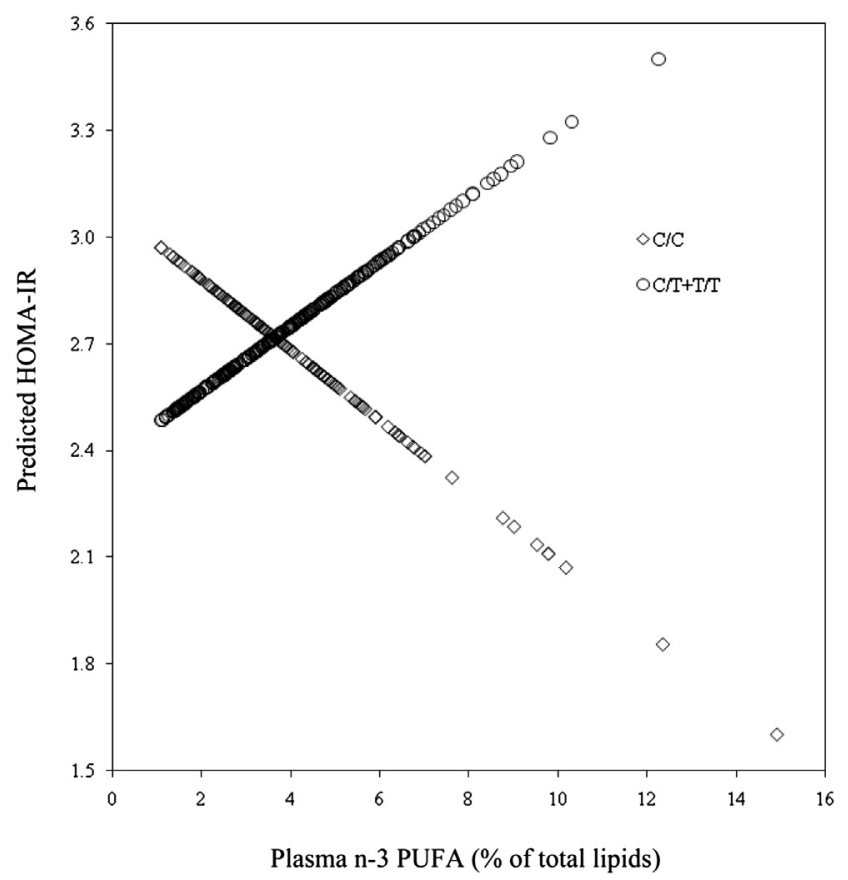

Fig. 2. Predicted values for homeostasis model assessment of insulin resistance (HOMA-IR) for the PCK1 rs2179706 polymorphism. A difference was observed between the genotypes, with the T-allele genotype group (circles) appearing to be "high responders" to the plasma concentration of omega- 3 polyunsaturated fatty acids $(n-3$ PUFA) and the C allele homozygote group (squares) appearing to be "low responders".

cardiovascular events, cardiac death and coronary events and also to reduce the risk of MetS. ${ }^{17-20}$ However, limited and inconsistent data are available concerning the relation between $n-3$ PUFA and glucose metabolism. Results from the Women's Health and the Nurses' Health studies, showed an increased risk of T2D, especially with high intake of $n-3$ PUFA. ${ }^{21,22}$ Recently Wu et al. conducted a meta-analysis concluding that $n-3$ PUFAs do not support either major harms or benefits on development of diabetes. ${ }^{23}$ However results from other meta-analysis indicate differences between geographical regions in relationship with dietary intake of $n-3$ PUFA and the risk of T2D, with an increased risk among studies conducted in the U.S., no association in European populations, and an inverse association in Asian/Australian populations. ${ }^{24}$ Thus, general recommendations may not be equally positive. Our present study shows for the first time an interaction between the PCK1 gene locus, plasma fatty acid and glucose metabolism in subjects with the MetS.

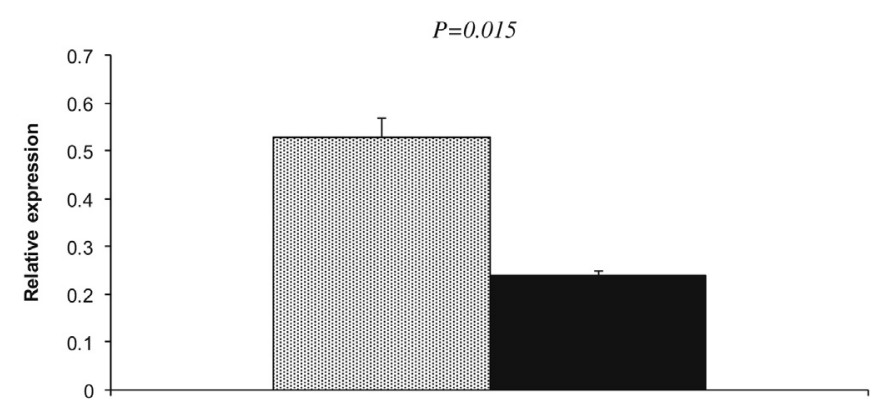

$$
\text { अ } \mathrm{C} / \mathrm{C}=\mathrm{C} / \mathrm{T}+\mathrm{T} / \mathrm{T}
$$

Fig. 3. PCK1 gene expression changes in adipose tissue of subjects with MetS and the rs2179706 polymorphism. Data are expressed as means \pm SE of relative expression ( $n=30,10$ homozygous C/C and 20 with the T-allele). Significant differences between groups were determined by one-way ANOVA.
As with many genetic association studies investigating polygenic diseases, the association between PCK1 polymorphisms and T2D has showed mixed results ${ }^{10,25-29}$ However, there is consistent evidence from animal models and human studies implicating that PEPCK-C is involved in the development of insulin resistance. ${ }^{30,31}$ Previous studies have demonstrated that PCK1 responds to a wide range of nutrients to maintain glucose and lipid homeostasis. ${ }^{32}$ In our study we observed a gene-fatty acid interaction among subjects with the rs2179706 SNP and plasma levels of $n-3$ PUFA to influence insulin resistance, suggesting the potential sensitivity of this SNP to dietary factors. Genetic variation promoting enhanced PCK1 transcription might lead to increased PEPCK-C enzymatic activity, which would increase insulin resistance through its effect on gluconeogenesis. For example, a mutation that impairs the ability of insulin to suppress hepatic PCK1 transcription would have this effect. By contrast, mutations that reducing hepatic PCK1 expression may cause hypoglycemia. ${ }^{33}$ Gomez-Valades et al. have shown that liver-specific silencing of PCK1 can improve glycaemic control, and insulin sensitivity in a diabetic mouse model, supports the role of PEPCK-C in T2D pathology and provides a potential target for treatment of the disease. ${ }^{30}$ On the other hand it has been suggested that T2D could be caused by reduced levels of PEPCK-C in adipose tissue. In our study we have shown that subjects carrying the T-allele had a lower PCK1 gene expression in the adipose tissue as compared with carriers of the $\mathrm{C} / \mathrm{C}$ genotype. This is relevant from a functional point of view because this SNP may influence PCK1 gene expression and corroborate previous evidence suggesting that lower expression in adipose tissue is related to insulin resistance and T2D. Based on these results we may speculate that $n-3$ PUFA fatty acids interact with the rs2179706 SNP, which may confer increased risk of insulin resistance by decreasing PCK1 gene expression in the adipose tissue. This is remarkable because insulin resistance is believed to be an important factor linking metabolic abnormalities in patients with the MetS.

Thus, our present study suggests an enhanced beneficial effect of increasing the amount of $n-3$ PUFA in the diet of $C / C$ subjects in comparison with those carrying the T-allele. Based on these data, and on the observed genotype-dependent associations, it is possible that a recommendation to increase dietary intake of $n-3$ PUFA could have a beneficial effect on insulin resistance only among MetS patients with the $\mathrm{C} / \mathrm{C}$ genotype, which might in turn have implications for cardiovascular risk. Despite the evidence, we should be cautious in the interpretation of our results. The LIPGENE cohort is very well characterized population, and the multicentre origin of the patients allows extrapolation of the results to the European population. The main limitation of our present study is that it is cross-sectional, without the possibility to prove causality. A second limitation is related to the SI. We did not find parallel results between HOMA-IR and SI, although IVGTT is a very well validated method to estimate insulin sensitivity.

In conclusion, our results support the notion that $n-3$ PUFA may play a contributing role in triggering insulin resistance by interacting with a genetic variant at PCK1 gene locus. Advances in the nutrigenomics are expected to open new ways in genomecustomized diets for MetS prevention.

\section{Statement of authorship}

Prof. Roche and Prof. Lopez-Miranda had full access to all of the data in the study and take responsibility for the integrity of the data and the accuracy of the data analysis. Conception and design of the study: P.P.-M., A.G.-R., H.M.R., J.L.-M. Provision of study materials or subjects: E.E.B., A.D.-K., C.D., U.R., W.H.M.S., J.A.L., C.A.D., H.M.R. and J.L.-M. Collection and assembly of data: J.D.-L., I.M.F.G., J.G., B.K., B.K.-W., A.C., E.E.B., O.H., W.H., C.D., U.R., W.H.M.S., J.A.L., C.A.D. 
Analysis and interpretation of the data: P.P.-M., A.G.-R., H.M.R. and J.L.-M. Statistical expertise: J.D.-L. and A.G.-R. Drafting of the manuscript: P.P.-M., A.G.-R., H.M.R. and J.L.-M. Critical review of the manuscript for important intellectual content: B.K., B.K.-W., E.E.B., O.H., A.D.-K., C.D., U.R., W.H.M.S., J.A.L., and C.A.D. All authors read and approved the final manuscript.

\section{Conflict of interest}

None of the authors has any conflict of interest that could affect the performance of the work or the interpretation of the data.

\section{Acknowledgments}

This study was supported in part by research grants from the European community (LIPGENE European Integrated Project505944), grants from the Spanish Ministry of Science and Innovation (AGL2006-01979/ALI, AGL2009-12270 to JL-M and PI10/01041 to PP-M), Consejería de Economía, Innovación y Ciencia, Proyectos de Investigación de Excelencia, Junta de Andalucía (P06-CTS-01425 to JL-M); Consejería de Salud, Junta de Andalucía (07/43, PI-0193/ 09 to JL-M, PI-0252/2009 to JD-L and PI-0058-2010 to PP-M), and the Johan Throne Holst Foundation for Nutrition Research and Freia Medical Research Fund, Norway. This study was also supported by Centro de Excelencia Investigadora en Aceite de Oliva y Salud (CEAS). HRM is a recipient by Science Foundation Ireland Principal Investigator Programme (06/IM.1/B105). AG-R is supported by a research contract of ISCIII (Programa Río-Hortega). The CIBEROBN is an initiative of the Instituto de Salud Carlos III, Madrid, Spain.

The study was registered with the US National Library of Medicine Clinical Trials registry (NCT00429195).

\section{Appendix A. Supplementary data}

Supplementary data related to this article can be found at http:// dx.doi.org/10.1016/j.clnu.2012.10.003.

\section{References}

1. Executive summary of the third report of the National Cholesterol Education Program (NCEP) expert panel on detection, evaluation, and treatment of high blood cholesterol in adults (Adult Treatment Panel III). JAMA May 16, 2001;285(19):2486-97.

2. Paniagua JA, Perez-Martinez P, Gjelstad IM, Tierney AC, Delgado-Lista J, Defoort C, et al. A low-fat high-carbohydrate diet supplemented with longchain $n-3$ PUFA reduces the risk of the metabolic syndrome. Atherosclerosis Oct 2011;218(2):443-50.

3. Perez-Martinez P, Garcia-Rios A, Delgado-Lista J, Perez-Jimenez F, LopezMiranda J. Mediterranean diet rich in olive oil and obesity, metabolic syndrome and diabetes mellitus. Curr Pharm Des 2011;17(8):769-77.

4. Lopez-Miranda J, Perez-Martinez P, Marin C, Fuentes F, Delgado J, PerezJimenez F. Dietary fat, genes and insulin sensitivity. J Mol Med (Berl) Mar 2007;85(3):213-26.

5. Perez-Martinez P, Garcia-Rios A, Delgado-Lista J, Perez-Jimenez F, LopezMiranda J. Metabolic syndrome: evidences for a personalized nutrition. Mol Nutr Food Res Jan 2012;56(1):67-76.

6. Perez-Martinez P, Delgado-Lista J, Garcia-Rios A, Ferguson JF, Gulseth HL, Williams CM, et al. Calpain-10 interacts with plasma saturated fatty acid concentrations to influence insulin resistance in individuals with the metabolic syndrome. Am J Clin Nutr May 2011;93(5):1136-41.

7. Perez-Martinez P, Delgado-Lista J, Garcia-Rios A, Mc Monagle J, Gulseth HL, Ordovas JM, et al. Glucokinase regulatory protein genetic variant interacts with omega-3 PUFA to influence insulin resistance and inflammation in metabolic syndrome. PLoS One 2011;6(6):e20555.

8. Hani EH, Zouali H, Philippi A, Beaudoin JC, Vionnet N, Passa P, et al. Indication for genetic linkage of the phosphoenolpyruvate carboxykinase (PCK1) gene region on chromosome $20 \mathrm{q}$ to non-insulin-dependent diabetes mellitus. Diabetes Metab Dec 1996;22(6):451-4.

9. Beale EG, Harvey BJ, Forest C. PCK1 and PCK2 as candidate diabetes and obesity genes. Cell Biochem Biophys 2007;48(2-3):89-95.
10. Cao H, van der Veer E, Ban MR, Hanley AJ, Zinman B, Harris SB, et al. Promoter polymorphism in PCK1 (phosphoenolpyruvate carboxykinase gene) associated with type 2 diabetes mellitus. J Clin Endocrinol Metab Feb 2004;89(2):898-903.

11. Millward CA, Desantis D, Hsieh CW, Heaney JD, Pisano S, Olswang Y, et al. Phosphoenolpyruvate carboxykinase (Pck1) helps regulate the triglyceride/ fatty acid cycle and development of insulin resistance in mice. J Lipid Res Jun 2010;51(6):1452-63.

12. Shaw DI, Tierney AC, McCarthy S, Upritchard J, Vermunt S, Gulseth HL, et al. LIPGENE food-exchange model for alteration of dietary fat quantity and quality in free-living participants from eight European countries. Br J Nutr Mar 2009;101(5):750-9.

13. Perez-Martinez P, Moreno-Conde M, Cruz-Teno C, Ruano J, Fuentes F, DelgadoLista J, et al. Dietary fat differentially influences regulatory endothelial function during the postprandial state in patients with metabolic syndrome: from the LIPGENE study. Atherosclerosis Apr 2010;209(2):533-8.

14. Matthews DR, Hosker JP, Rudenski AS, Naylor BA, Treacher DF, Turner RC. Homeostasis model assessment: insulin resistance and beta-cell function from fasting plasma glucose and insulin concentrations in man. Diabetologia Jul 1985;28(7):412-9.

15. Boston RC, Stefanovski D, Moate PJ, Sumner AE, Watanabe RM, Bergman RN. MINMOD Millennium: a computer program to calculate glucose effectiveness and insulin sensitivity from the frequently sampled intravenous glucose tolerance test. Diabetes Technol Ther 2003;5(6):1003-15.

16. Phillips CM, Goumidi L, Bertrais S, Ferguson JF, Field MR, Kelly ED, et al. Complement component 3 polymorphisms interact with polyunsaturated fatty acids to modulate risk of metabolic syndrome. Am J Clin Nutr Dec 2009;90(6):1665-73.

17. Albert CM, Campos H, Stampfer MJ, Ridker PM, Manson JE, Willett WC, et al. Blood levels of long-chain $n-3$ fatty acids and the risk of sudden death. $N$ Engl $J$ Med Apr 11 2002;346(15):1113-8.

18. Delgado-Lista J, Perez-Martinez P, Lopez-Miranda J, Perez-Jimenez F. Long chain omega-3 fatty acids and cardiovascular disease: a systematic review. $\mathrm{Br} J$ Nutr Jun 2012;107(Suppl 2):S201-13.

19. Jenkins DJ, Josse AR, Dorian P, Burr ML, LaBelle Trangmar R, Kendall CW, et al. Heterogeneity in randomized controlled trials of long chain (fish) omega-3 fatty acids in restenosis, secondary prevention and ventricular arrhythmias. J Am Coll Nutr Jun 2008;27(3):367-78.

20. Mirmiran P, Hosseinpour-Niazi S, Naderi Z, Bahadoran Z, Sadeghi M, Azizi F. Association between interaction and ratio of omega- 3 and omega- 6 polyunsaturated fatty acid and the metabolic syndrome in adults. Nutrition Sep 2012;28(9):856-63.

21. Kaushik M, Mozaffarian D, Spiegelman D, Manson JE, Willett WC, Hu FB. Long-chain omega-3 fatty acids, fish intake, and the risk of type 2 diabetes mellitus. Am J Clin Nutr Sep 2009;90(3):613-20.

22. Djousse L, Gaziano JM, Buring JE, Lee IM. Dietary omega-3 fatty acids and fish consumption and risk of type 2 diabetes. Am J Clin Nutr Jan 2011;93(1):143-50.

23. Wu JH, Micha R, Imamura F, Pan A, Biggs ML, Ajaz O, et al. Omega-3 fatty acids and incident type 2 diabetes: a systematic review and meta-analysis. Br J Nutr Jun 2012;107(Suppl. 2):S214-27.

24. Wallin A, Di Giuseppe D, Orsini N, Patel PS, Forouhi NG, Wolk A. Fish consumption, dietary long-chain $n-3$ fatty acids, and risk of type 2 diabetes: systematic review and meta-analysis of prospective studies. Diabetes Care Apr 2012;35(4):918-29.

25. Wegner L, Andersen G, Albrechtsen A, Sparso T, Glumer C, Borch-Johnsen K, et al. Large-scale study of the $-232 \mathrm{C}>\mathrm{G}$ polymorphism of PCK1 in type 2 diabetes. Diabet Med Oct 2006;23(10):1140-4.

26. Horikawa Y, Yamasaki T, Nakajima H, Shingu R, Yoshiuchi I, Miyagawa J, et al. Identification of a novel variant in the phosphoenolpyruvate carboxykinase gene promoter in Japanese patients with type 2 diabetes. Horm Metab Res May 2003;35(5):308-12.

27. Shin HD, Park BL, Kim LH, Cheong HS, Kim JH, Cho YM, et al. Association of a polymorphism in the gene encoding phosphoenolpyruvate carboxykinase 1 with high-density lipoprotein and triglyceride levels. Diabetologia Oct 2005;48(10):2025-32.

28. Rees SD, Britten AC, Bellary S, O'Hare JP, Kumar S, Barnett AH, et al. The promoter polymorphism $-232 \mathrm{C} / \mathrm{G}$ of the PCK1 gene is associated with type 2 diabetes in a UK-resident South Asian population. BMC Med Genet 2009;10:83.

29. Willer CJ, Bonnycastle LL, Conneely KN, Duren WL, Jackson AU, Scott LJ, et al. Screening of 134 single nucleotide polymorphisms (SNPs) previously associated with type 2 diabetes replicates association with 12 SNPs in nine genes. Diabetes Jan 2007;56(1):256-64.

30. Gomez-Valades AG, Mendez-Lucas A, Vidal-Alabro A, Blasco FX, Chillon M, Bartrons R, et al. Pck1 gene silencing in the liver improves glycemia control, insulin sensitivity, and dyslipidemia in db/db mice. Diabetes Aug 2008;57(8): 2199-210.

31. Beale EG, Hammer RE, Antoine B, Forest C. Disregulated glyceroneogenesis: PCK1 as a candidate diabetes and obesity gene. Trends Endocrinol Metab Apr 2004;15(3):129-35.

32. Tordjman J, Khazen W, Antoine B, Chauvet G, Quette J, Fouque F, et al. Regulation of glyceroneogenesis and phosphoenolpyruvate carboxykinase by fatty acids, retinoic acids and thiazolidinediones: potential relevance to type 2 diabetes. Biochimie Dec 2003;85(12):1213-8.

33. Reshef L, Olswang Y, Cassuto H, Blum B, Croniger CM, Kalhan SC, et al. Glyceroneogenesis and the triglyceride/fatty acid cycle. J Biol Chem Aug 15 2003;278(33):30413-6. 